\title{
Small macrobenthic invertebrates affect the mortality and growth of early post-settlement sea urchins and sea stars in subtidal cobble habitat
}

\author{
Lindsay B. Jennings ${ }^{*}$, Heather L. Hunt \\ Department of Biology, University of New Brunswick, Saint John, New Brunswick E2L 4L5, Canada
}

\begin{abstract}
Early post-settlement events can have a large impact on the successful recruitment of benthic invertebrates. A field caging experiment was conducted in 2007 to examine whether predation by, and/or competition with, small macrofauna affects mortality or growth of recently settled sea urchins Strongylocentrotus droebachiensis or sea stars Asterias spp. Kelp was added to half of the sea urchin cages to test whether the addition of this food source (including its associated biofilms) altered growth or survival. Sea urchins survived $25 \%$ better in cages where the other organisms were removed, indicating that predation or bulldozing likely plays an important role. The growth of sea urchins was greatest in cages without other organisms and lowest in cages with other organisms and with food, possibly indicating competition that affects sea urchin behaviour. Sea stars showed the opposite trend in survival. A greater proportion of sea stars survived in cages where the other organisms were present (31.3 vs. $11.5 \%$ ), presumably due to them being a food source for the sea stars, indicating that starvation, cannibalism and/or competition for food are likely important for recent settlers of this taxon. The declines in abundance in the cages were greater than those in the natural environment for sea urchins, but similar for sea stars, suggesting that caution is required when extrapolating experimental results to the field. These results indicate that multiple factors, which differ between these species, affect early post-settlement growth and mortality.
\end{abstract}

KEY WORDS: Strongylocentrotus droebachiensis · Asterias spp. · Mortality · Growth · Predation · Competition · Early post-settlement · Natural declines

\section{INTRODUCTION}

The period just after settlement is a vulnerable time for benthic marine invertebrates (reviewed by Gosselin \& Qian 1997, Hunt \& Scheibling 1997). Interactions with their new physical environment, such as wave action and desiccation, as well as with other organisms can negatively affect recently settled individuals (Gosselin \& Qian 1997, Hunt \& Scheibling 1997). Mortality is extremely high for juvenile invertebrates, often exceeding $90 \%$, and predation, usually by larger epibenthic carnivores, has been the causal mechanism most frequently investigated (Gosselin \& Qian 1997). Predation has been shown to dramatically reduce abundances (reviewed by Gosselin \& Qian
1997, Hunt \& Scheibling 1997), with mortality rates exceeding $30 \%$ and occasionally reaching $100 \%$ for some species (Griffiths \& Gosselin 2008, Scheibling \& Robinson 2008).

While research has focused on predation by carnivores as the most important source of mortality in juvenile benthic invertebrates, there are many other potential sources, including consumption by grazing omnivores, physical damage without consumption (bulldozing) and competition. For example, gut analyses of chitons (Langer 1983) and sea urchins (Briscoe \& Sebens 1988) have found both algal and animal biomass. Large numbers of recently settled barnacles can be dislodged and die due to the bulldozing activity of limpets (Dayton 1971). Creese (1982) observed up to 
$90 \%$ mortality in juvenile limpets due to interspecific competition, an amount comparable to predation.

However, competition does not have to be fatal, and may be more likely to have sublethal impacts on processes such as growth or fecundity (Birch 1957, Tomas et al. 2005). Intraspecific competition can reduce growth at high densities (e.g. Marsden 2002, Silina 2008) or reduce growth rates for small individuals forced to compete with larger ones (e.g. Kautsky 1982). Reduced growth rates can prolong the time it takes to reach recruitment (if defined by size) and sexual maturity.

When predation and competition are examined together, the presence of predators often results in a greater reduction in abundance, fecundity and growth than does the presence of competitors (e.g. Aukema \& Raffa 2002, Beal 2006). However, few studies have examined the effects of both predation and competition on juveniles. In the sea urchin Evechinus chloroticus, juveniles had higher densities when predators were excluded, regardless of the presence of adult conspecifics (Andrew \& Choat 1982). Beal (2006) found that, while both predation and intraspecific competition had significant impacts on the survival of juvenile clams Mya arenaria, predation accounted for $45 \%$ of the variability in survival and intraspecific competition accounted for only $2 \%$. However, growth of these juvenile clams was not significantly affected by either predation or intraspecific competition (Beal 2006).

The relative importance of predation and competition may also depend on the habitat, as some habitats (e.g. subtidal rocky barrens vs. kelp beds) have fewer predators than others (McNaught 1999). Rocky barrens with coralline algae and cobbles are one of the predominant shallow subtidal habitats in the southwestern Bay of Fundy, North Atlantic. Sea urchins and sea stars are 2 mobile species with different ecological niches that are both common on the same subtidal cobble habitat in this area (Jennings \& Hunt 2009). Small sea urchins tend to be cryptic, which, while protecting them from larger predators, exposes them to the suite of smaller organisms living amongst cobbles (reviewed by Scheibling 1996). Cobble habitats in the southwestern Bay of Fundy host a suite of small macrobenthic invertebrates that include many potential predators, both carnivorous and omnivorous, and competitors of juvenile sea urchins and sea stars (Jennings \& Hunt 2009). While previous research has tended to examine larger carnivores such as decapods as potential predators of small echinoderms (e.g. Scheibling \& Robinson 2008), studies done in the Pacific indicate that the community of small organisms living among coral rubble can reduce abundances of recently settled sea stars (Acanthaster planci and Nardoa novaecaladoniae) (Keesing \& Halford 1992, Keesing et al. 1996).
The present study examined early post-settlement mortality and growth of echinoderms. We used field caging experiments to test the hypothesis that interactions (predation and interspecific competition) with the suite of small macrobenthic invertebrates living amongst subtidal cobbles increase mortality of recently settled sea urchins Strongylocentrotus droebachiensis and sea stars Asterias spp. and decrease growth of the sea urchins. For the sea urchin experiment, we ran treatments with and without additional food (kelp) to help tease apart the effects of predation and competition (inter- and intraspecific). We identified the species in the suite to determine possible predators, both carnivorous and omnivorous, and competitors. In addition, we sampled the natural cobble communities concurrently with the field experiments to be able to compare natural rates of decline of recently settled sea urchins and sea stars to those in the caging experiments.

\section{MATERIALS AND METHODS}

Study site. This study took place at Dick's Island $\left(45^{\circ} 08.507^{\prime} \mathrm{N}, 67^{\circ} 00.105^{\prime} \mathrm{W}\right)$ in Passamaquoddy Bay, Bay of Fundy, New Brunswick, Canada. The rocky subtidal site was chosen based on the presence of adult sea cucumbers, sea urchins, sea stars and brittle stars, indicating that it represented a suitable habitat for these species of echinoderms. The substrate was composed of small cobbles covered in coralline algae. The mean water depth at this site was approximately $7 \mathrm{~m}$ at high tide and $2 \mathrm{~m}$ at low tide, and there was no strong current (average current in this area is $\sim 0.07 \mathrm{~m} \mathrm{~s}^{-1}$; Blythe Chang, Dept. of Fisheries and Oceans, Canada, pers. comm.).

Caging experiment. The cages were $23 \times 23 \times 9 \mathrm{~cm}$ plastic containers with removable lids made by ERA ware. Holes $(13 \times 5 \mathrm{~cm})$ were cut on all 4 sides of each container, 2 holes $(14 \times 4 \mathrm{~cm})$ were cut in the lid and all holes were covered with $750 \mu \mathrm{m}$ Nitex mesh to allow water flow but prevent escape of the organisms. As the sea urchins Strongylocentrotus droebachiensis and sea stars Asteria spp. added to these cages were larger than the Nitex mesh, they could only escape if the cage was damaged. No cages were damaged or lost during this experiment, although 1 sea star cage (with-suite treatment) was excluded from analysis (see below). These cages were filled with approximately 30 rocks with a mean $( \pm \mathrm{SE})$ surface area of $8340 \pm 477 \mathrm{~mm}^{2}$ and a $35.5 \pm 2.4 \%$ cover of live coralline algae.

Sea urchin experiment. Newly settled sea urchins Strongylocentrotus droebachiensis (1 to $3 \mathrm{~mm}$ ) were obtained from the field $1 \mathrm{~km}$ from the experimental site in August 2007 and held in the laboratory for $8 \mathrm{~d}$. Sea urchins were marked in the laboratory with calcein, a 
fluorescent dye that binds to the calcium added to the skeletal structures of the animal, such as the test and Aristotle's lantern (mouthparts). The sea urchins were placed in an aquarium with $0.625 \mathrm{~g}$ of calcein in $30 \mathrm{l}$ of seawater buffered with $0.5 \mathrm{~g}$ of sodium bicarbonate (Russell 2001) for 7 d, since no mark was visible after $24 \mathrm{~h}$ in a preliminary trial.

Two factors were manipulated in the experiment: presence of the suite of small benthic invertebrates found amongst the cobbles and food (kelp, Saccharina longicruris and associated biofilms). The cages were set up in situ underwater. In half of the cages, all the rocks and the suite of small benthic invertebrates in a $25 \times 25 \mathrm{~cm}$ quadrat next to the cage location were placed into each cage. This suite of sessile and mobile benthic invertebrates consisted of animals of from 0.1 to $35 \mathrm{~mm}$ in size, living among the shallow-water cobbles, including molluscs, polychaetes, echinoderms and tunicates (see Jennings 2011 for complete list of species and sizes). For the no-suite treatment, the rocks from the quadrats were brought to the surface and cleaned of all visible animals and then the cleaned rocks were placed in the cages. Food, 3 pieces of the kelp Saccharina longicruris and associated biofilms $(10 \times 5 \mathrm{~cm})$, was placed into half of the cages. Small juvenile Strongylocentrotus spp. consume kelp when they are older than a month and a half (Rowley 1990, Harris et al. 1994, Jennings 2011). There were 4 treatment combinations: (1) with suite/with food, (2) with suite/no food, (3) no suite/with food and (4) no suite/no food. Seven replicates of each treatment combination were deployed for a total of 28 cages.

Once the treatment combinations were set up underwater, 20 sea urchins (1 to $3 \mathrm{~mm}$ test diameter) were added to each cage and the lid was put on. The cages remained in the water for $9 \mathrm{wk}$ (end of August to end of October 2007). The Nitex mesh on the cages was cleaned of epiphytes and debris at the end of the third week. At the end of the experiment, the cages were removed from the water and frozen to preserve the community before processing. All rocks in the cages were examined, brushed off and rinsed to ensure all animals were removed. All benthic invertebrates were identified and counted using a dissecting microscope. Each sea urchin $<8 \mathrm{~mm}$ was soaked in $5 \%$ sodium hypochlorite to dissolve the soft tissues so the demipyramids (jaws) of the Aristotle's lantern could be removed. After being rinsed in fresh water, the demipyramids were air dried before being examined under a dissecting microscope with ultraviolet light (365 and $254 \mathrm{~nm}$ ) for the calcein mark.

Calcein is a commonly used marking technique in sea urchins and does not affect growth or mortality (Lamare \& Mladenov 2000, Ebert 2001, Russell 2001, Russell \& Urbaniak 2004, Jennings 2011). After $4.5 \mathrm{wk}$ in the laboratory, in a blind identification trial, we found a calcein mark on $98 \%$ of the marked sea urchins (49/50) and correctly identified unmarked sea urchins $100 \%$ of the time (50/50). Therefore, in the field experiment, only those individuals showing a calcein mark were counted as surviving sea urchins. Any unmarked sea urchins in the cages were considered to be part of the suite of animals. New growth since the start of the experiment is between the calcein mark and the epiphysis junction. The new growth was divided by the original size (distance between the oral tip and the calcein mark) to get the percentage growth of the demi-pyramid during the experiment. All measurements were done using the image analysis software Perfect Screen Ruler 2.0.

Sea star experiment. Newly settled sea stars $(0.5$ to $1.5 \mathrm{~mm}$ arm tip to opposite side of body) were collected from Beaver Harbour, New Brunswick, $20 \mathrm{~km}$ from the experimental site, in September 2007 and held in the laboratory for $8 \mathrm{~d}$. The sea stars consisted of 2 congeneric species, Asterias rubens and A. forbesi, that could not be distinguished morphologically at this size. In a previous study, interspecific competition between these 2 species did not significantly affect feeding rates or growth in laboratory experiments (Menge 1979). Due to the very low abundance of juvenile sea stars at Dick's Island in autumn (Jennings \& Hunt 2009), the marking of sea stars with calcein was not required. Due to cannibalism in the laboratory prior to the experiment, only 1 factor (presence/absence of the suite of animals) could be tested, with 6 replicates per treatment. Rocks for the no-suite treatment were collected $8 \mathrm{~d}$ before the experiment, cleaned of animals in the laboratory and soaked in seawater to ensure the coralline algae and the microbial biofilm were alive during the experiment. Cages were set up in situ underwater. Into half of the cages, we placed all the rocks and the suite of small benthic invertebrates in a $25 \times 25 \mathrm{~cm}$ quadrat next to each cage. In the remaining cages, we placed the cleaned rocks. Sixteen sea stars were then placed into each cage, and the lids were closed. The cages remained underwater for $5 \mathrm{wk}$ (end of September to end of October 2007) before being removed and frozen to preserve the community before processing as described above for the urchin experiment.

Natural community. At the same times that the cages were deployed and retrieved (August, September and October), all the rocks and animals in 7 (August and October) or 5 (September) quadrats $(25 \times 25 \mathrm{~cm})$ randomly positioned nearby were also collected to determine the natural community associated with cobbles in the area at the beginning and end of the experiment. These samples were frozen until processing, as described for the urchin experiment. Spirorbid abundances were not included in the community analyses, as the brushing technique did 
not result in reliable counts of these animals. Sea urchins $<2.2 \mathrm{~mm}$ in August, $<2.5 \mathrm{~mm}$ in September and $<2.9 \mathrm{~mm}$ in October 2007 were considered young-of-the-year, having settled in 2007, based on peaks in size-frequency diagrams (Fig. 1). These sizes are similar to the size classes used in Jennings \& Hunt (2009), based on data at the same site a few years earlier. Sea stars $<3.5 \mathrm{~mm}$ in August, $<4.5 \mathrm{~mm}$ in September and $<5 \mathrm{~mm}$ in October 2007 were considered as young-of-the-year based on the few small sea stars found in the quadrat samples and Jennings \& Hunt (2009).

Statistical analysis. The abundances of the species in quadrats of the natural community and in the cages for both the sea urchin and sea star experiments were compared using a Bray-Curtis similarity index and multi-dimensional scaling (MDS) ordination. An analysis of similarities (ANOSIM) was performed on the Bray-Curtis similarity matrix to determine differences between communities inside and outside of the cages
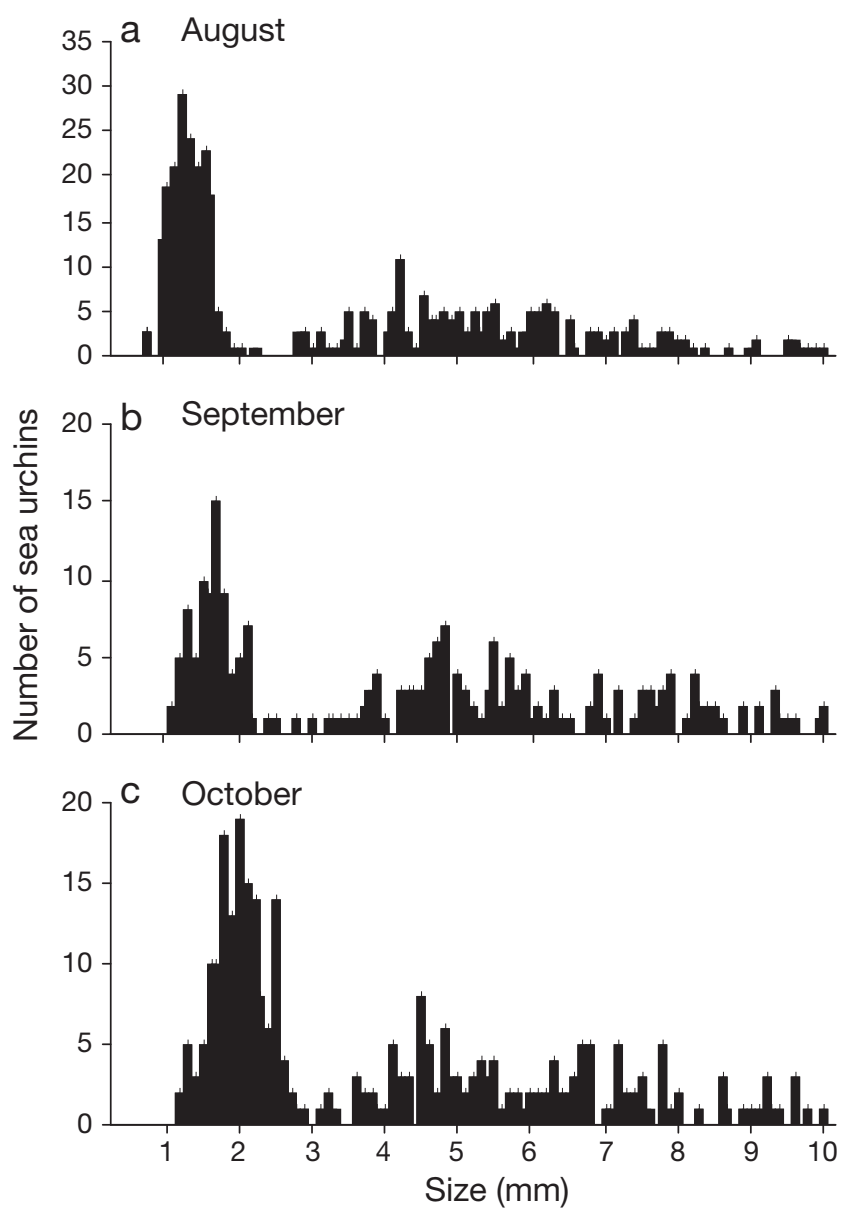

Fig. 1. Strongylocentrotus droebachiensis. Size-frequency diagrams (based on test diameter) of juvenile sea urchins in (a) August $(\mathrm{n}=368)$, (b) September $(\mathrm{n}=222)$ and (c) October 2007 ( $\mathrm{n}=291$ ). Number of sea urchins is cumulative from seven $0.0625 \mathrm{~m}^{2}$ quadrats in August and October and 5 quadrats in September and between the with-suite and no-suite communities within the cages. ANOSIM is a non-parametric permutation technique that compares groups based on a similarity matrix and produces an R-value indicating the amount of segregation between groups (Clarke \& Warwick 2001). R usually ranges from 0 (groups overlap) to 1 (groups are completely segregated) (Clarke \& Warwick 2001). SIMPER (a method using similarity percentages) was used to determine the species most responsible for the differences between communities.

The numbers of sea urchins remaining in the cages were analyzed using a 2-factor analysis of variance (ANOVA), with suite of organisms in the cobbles and the addition of food as fixed factors. The variances were homogeneous $\left(\mathrm{O}^{\prime}\right.$ Brien [0.5] test: $F_{3,24}=1.39, \mathrm{p}=$ 0.271 ). Growth of the sea urchin demi-pyramids was analyzed using a nested ANOVA, since growth was measured for multiple sea urchins in each cage. Suite of animals and food were fixed factors, while cage nested within suite $\times$ food was a random factor. The variances were homogeneous $\left(\mathrm{O}^{\prime}\right.$ Brien $[0.5]$ test: $F_{26,270}=0.79, \mathrm{p}=0.759$ ).

A 2-sample $t$-test was used to compare the numbers of sea stars remaining in the cages in the presence and absence of the suite of invertebrates. One sea star replicate was excluded because it was the only one that contained a large sea star in the suite and had a lower recovery rate of the transplanted sea stars than any of the other replicates. Exclusion of this replicate resulted in a significant result being obtained (excluding cage $p=0.007$, including cage $p=0.102$ ). The sea star variances were homogeneous $\left(\mathrm{O}^{\prime}\right.$ Brien $[0.5]$ test: $\left.F_{1,8}=2.57, \mathrm{p}=0.148\right)$.

The natural densities of sea urchins and sea stars were compared among months (August, September and October) using 1-factor ANOVAs. The variances were homogeneous $\left(\mathrm{O}^{\prime}\right.$ Brien [0.5] test, sea urchins: $F_{2,16}=0.73, \mathrm{p}=0.496$; sea stars: $F_{2,16}=1.08, \mathrm{p}=0.362$ ). The percent decline of the number of small sea urchins and sea stars in with-suite cages was compared to that in the natural environment over the same time period (sea urchins: August to October; sea stars: September to October) using $t$-tests. The food treatments were pooled because this factor had no significant effect on the number of sea urchins remaining in the cages (see 'Results' section). Because quadrats of the natural communities were destructively sampled, quadrats cannot be paired between sampling periods. Therefore, to obtain percent decline in abundance of young-of-theyear sea urchins and sea stars in the quadrats, the difference between the mean number of young-of-theyear in August (September for sea stars) and the number in each October quadrat was divided by the mean number in August (September for sea stars). Arcsine-square-root transformations were performed on 
the sea urchin data to increase the homogeneity of the variances (O'Brien [0.5]: $F_{1,19}=4.57, \mathrm{p}=0.046$ ). Variances were homogeneous for the sea star data $\left(\mathrm{O}^{\prime}\right.$ Brien [0.5]: $\left.F_{1,9}=0.61, \mathrm{p}=0.456\right)$.

All univariate statistics were done using JMP 5.0.1. All multivariate statistics were done using PRIMER 5.

\section{RESULTS}

\section{Communities}

The communities were composed of 21 to 33 species (86 species overall), with most individuals being $<35 \mathrm{~mm}$ in size (Jennings 2011). The communities of animals in the cages with the suite were more similar to the natural communities outside the cages than to the cages with no suite (Fig. 2), both of them being dominated by sea urchins and chitons. While the cages with no suite started with cleaned rocks, after 5 or 9 wk many different species had settled in the cages, including the tunicate Ciona intestinalis, various species of bivalves, limpets, chitons and amphipods. The ANOSIM revealed differences between the communities (Global $\mathrm{R}=0.707$; $\mathrm{p}=0.001$ ). Cages with the suite were very different from those without the suite for sea urchins Strongylocentrotus droebachiensis (regardless of whether food was present or not) and sea stars Asteria spp. (Table 1). SIMPER pairwise comparisons indicated that, across all comparisons, these differences were driven primarily by unmarked sea urchins S. droebachiensis (14.96 to $18.17 \%$ ), as well as chitons Tonicella rubra (7.79 to $15.84 \%$ ) and T. marmorea (4.74 to $6.50 \%$ ) and a few tunicates C. intestinalis $(5.61$ to $8.90 \%)$ in the with-suite treatments. In the comparisons among sea urchin cages, the bivalves Hiatella arctica and Anomia simplex had lower abundances in the with-suite treatment combinations, contributing to the differences between treatment combinations ( 3.77 to $7.39 \%$ and 7.79 to $11.49 \%$, respectively). In the comparisons among sea star cages, encrusting bryozoans were less abundant and the scale worm Harmothoe imbricata was more abundant in the with-suite treatment, contributing to the differences between treatments (10.35 and $5.61 \%$, respectively).

The suites of animals inside the cages were only slightly different from the natural suites throughout the experiment. The differences between the natural communities and the with-suite cages were much more subtle than those between the with-suite and nosuite cages (Table 1, Fig. 2). For the sea urchin experiment, cages with the suite of animals and with food were not very different from the natural suite in August (beginning of experiment) or October (end of experiment) (Table 1, Fig. 2). The sea urchin cages with the suite but no food also did not differ greatly from the natural suite in August, but differed more

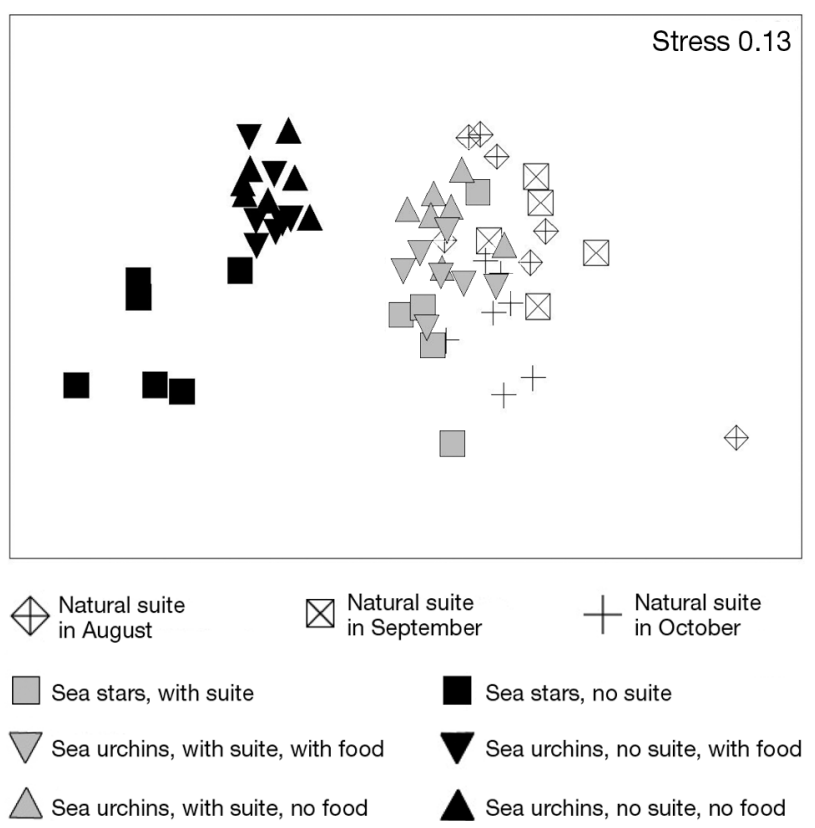

Fig. 2. Strongylocentrotus droebachiensis and Asteria spp. MDS plot of the assemblage of animals in each sample using a Bray-Curtis similarity index. Samples are quadrats (natural suite) and the various cage treatment combinations (with and without the suite of animals; with and without the addition of kelp) in the sea urchin and sea star experiments

Table 1. Strongylocentrotus droebachiensis and Asterias spp. Pairwise comparisons for analysis of similarities (ANOSIM) between the communities in the cages and the natural community at the beginning and end of both the sea urchin and sea star experiments. The overall ANOSIM was significant (Global $\mathrm{R}=0.707, \mathrm{p}=0.001$ )

\begin{tabular}{|lcc|}
\hline & $\mathrm{R}$ & $\mathrm{p}$ \\
\hline Sea urchins & & \\
With suite, no food vs. no suite, no food & 1.000 & 0.003 \\
With suite, no food vs. no suite, with food & 0.998 & 0.001 \\
With suite, with food vs. no suite, no food & 0.995 & 0.001 \\
With suite, with food vs. no suite, with food & 0.991 & 0.001 \\
Beginning natural (Aug) vs. with suite, no food & 0.190 & 0.020 \\
Beginning natural (Aug) vs. with suite, with food & 0.373 & 0.004 \\
End natural (Oct) vs. with suite, no food & 0.612 & 0.001 \\
End natural (Oct) vs. with suite, with food & 0.383 & 0.003 \\
Sea stars & & \\
With suite vs. no suite & 0.984 & 0.002 \\
Beginning natural (Sep) vs. with suite & 0.376 & 0.016 \\
End natural (Oct) vs. with suite & 0.408 & 0.001 \\
\hline
\end{tabular}


strongly from the natural suite in October (Table 1, Fig. 2). For the sea star experiment, cages with the suite had only small differences in community structure from the natural communities in September (beginning) or October (end) (Table 1, Fig. 2).

\section{Sea urchins}

There were significantly more sea urchins surviving in cages where the suite of natural organisms living on the cobbles had been removed (mean $\pm \mathrm{SE}_{;} 15.8 \pm 1.0$ ) than in cages where the other animals were present $(10.7 \pm 1.0)$ (Fig. 3 ; 2 -factor ANOVA: $F_{1,24}=13.85, \mathrm{p}=$ 0.001 ). The addition of food did not affect the number of sea urchins surviving, nor was there an interaction between the presence of the suite and added food (2-factor ANOVA: food $F_{1,24}=0.02, \mathrm{p}=0.876$; interaction $F_{1,24}=0.99, \mathrm{p}=0.329$ ).

There was a significant interaction between the presence of the suite of other animals and the addition of food for the growth of the sea urchin demipyramids (Fig. 4, Table 2). The sea urchin demi-pyramids grew significantly more when no suite was present than in cages with other benthic invertebrates; however, when the suite of animals was present, the sea urchin demi-pyramids grew better without added kelp (Fig. 4, Table 2; Tukey's post hoc test). The demi-pyramids of the sea urchins were 77.6 $\pm 1.5 \%$ larger at the end of the experiment in the cages with no suite of other animals, $51.6 \pm 2.3 \%$

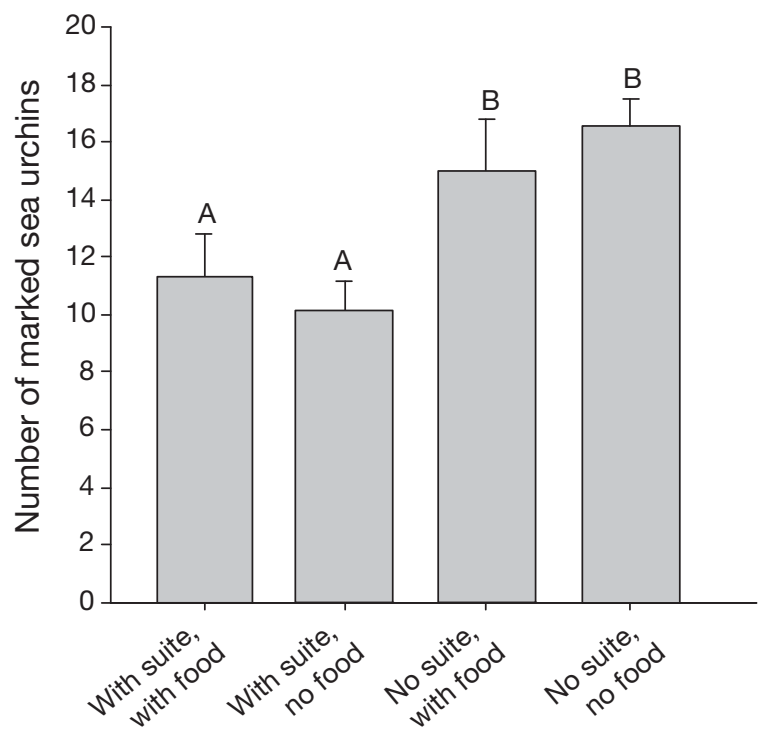

Fig. 3. Strongylocentrotus droebachiensis. The number (+SE) of marked sea urchins remaining in the cages after $9 \mathrm{wk}$. Twenty sea urchins were added to each cage. Bars marked by different letters are significantly different from one another $(\mathrm{n}=7)$

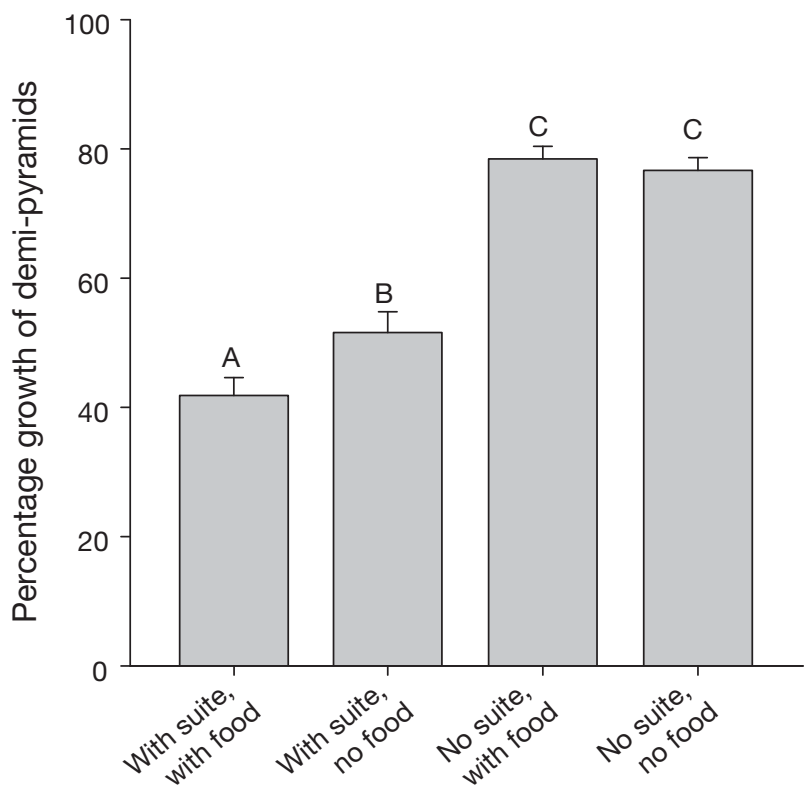

Fig. 4. Strongylocentrotus droebachiensis. The percentage growth $(+\mathrm{SE})$ of the demi-pyramids of marked sea urchins at the end of $9 \mathrm{wk}$ in the cages. The new growth was divided by the original size of the demi-pyramid. Bars marked by different letters are significantly different from one another $(n=7)$

larger with the suite and no food and $42.7 \pm 2.3 \%$ with the suite and with food.

The numbers of young-of-the-year (settled in 2007) sea urchins in the natural environment were not significantly different between months (Table 3; 1-factor ANOVA: $\left.F_{2,16}=1.23, \mathrm{p}=0.319\right)$. When the percent decline (August to October) was compared between the quadrats and the with-suite cages, the declines in the cages with the suite of other animals $(46.4 \pm 4.5 \%)$ were significantly larger than the natural declines $(18.9 \pm 12.0 \%)\left(t\right.$-test: $\left.t_{19}=2.53, \mathrm{p}=0.020\right)$.

\section{Sea stars}

In contrast to the sea urchin experiment, there were significantly more sea stars surviving in cages where the suite of natural organisms living on the cobbles was present $(4.8 \pm 1.1)$ than in cages where the other animals had been removed $(2.0 \pm 0.4)\left(t\right.$-test: $t_{8}=-3.6$, $p=0.007$ ). The number of young-of-the-year sea stars in quadrats at the study site did not differ significantly between months (Table 3; 1-factor ANOVA: $F_{2,16}=$ $1.47, \mathrm{p}=0.260$, power 0.46 to detect a $50 \%$ decline). When the percent decline (September to October) of sea star abundance was compared to that in the experiment, there was no significant difference between the natural environment $(76.2 \pm 23.8 \%)$ and the cages $(68.8 \pm 5.7 \%)\left(t\right.$-test: $\left.t_{9}=0.229, \mathrm{p}=0.824\right)$. 
Table 2. Strongylocentrotus droebachiensis. Nested analysis of variance (ANOVA) for the percent growth of the demi-pyramids of the marked sea urchins in the cages. Cage was a random factor nested in the fixed factors presence of suite (S) and presence of food (F). ${ }^{*}$ significance at $\alpha=0.05$

\begin{tabular}{|lrrcrc|}
\hline $\begin{array}{l}\text { Source of } \\
\text { variation }\end{array}$ & df & MS & $\begin{array}{c}\text { Denominator } \\
\text { for F-ratio }\end{array}$ & $F$ & $p$ \\
\hline Suite & 1 & 46232.64 & Cage $(\mathrm{S} \times \mathrm{F})$ & 139.45 & $<0.0001^{*}$ \\
Food & 1 & 641.39 & Cage $(\mathrm{S} \times \mathrm{F})$ & 2.34 & 0.1391 \\
Suite $\times$ Food & 1 & 1427.40 & Cage $(\mathrm{S} \times \mathrm{F})$ & 4.86 & $0.0373^{*}$ \\
Cage $(\mathrm{S} \times \mathrm{F})$ & 23 & 347.96 & Error & 1.44 & 0.0885 \\
Error & 260 & 243.85 & & & \\
\hline
\end{tabular}

Table 3. Strongylocentrotus droebachiensis and Asterias spp. Number of young-of-the-year sea urchins and sea stars per $0.0625 \mathrm{~m}^{2}$ quadrat at the study site in August, September and October 2007 (mean $\pm \mathrm{SE}, \mathrm{n}=5$ or 7 )

\begin{tabular}{|lrrr|}
\hline & \multicolumn{1}{c}{ Aug } & \multicolumn{1}{c|}{ Sep } & \multicolumn{1}{c|}{ Oct } \\
\hline Sea urchins & $26.4 \pm 4.9$ & $16.4 \pm 5.0$ & $21.4 \pm 3.2$ \\
Sea stars & $1.0 \pm 0.5$ & $0.6 \pm 0.2$ & $0.1 \pm 0.1$ \\
\hline
\end{tabular}

\section{DISCUSSION}

Recently settled green sea urchins Strongylocentrotus droebachiensis had $25 \%$ greater survival without the suite of small macrobenthic invertebrates that live amongst the cobbles. The most likely explanations for this result are competition, predation and bulldozing.

There were many potential competitors of recently settled sea urchins in the cages, such as other sea urchins, chitons and limpets. While the added kelp was a limited resource in the with-suite cages (none remaining at the end of the experiment-authors' pers. obs.), the addition of kelp as food did not increase sea urchin survival in any of the cages, implying that interspecific or intraspecific competition for kelp is not substantial in this system. Sea urchins were likely sustained by another food source, such as biofilms, coralline algae, or other settler invertebrates (e.g. Briscoe \& Sebens 1988, Rowley 1990, Harris et al. 1994).

Predation is the most examined cause of mortality in small juveniles, and most of these studies consider larger carnivorous predators (Gosselin \& Qian 1997, Hunt \& Scheibling 1997). However, there were not many potential carnivorous predators of small sea urchins in the cages in the present study. Small decapods are important predators, and can consume up to $100 \%$ of newly settled sea urchins (McNaught 1999, Scheibling \& Robinson 2008). No crabs and very few shrimp were found in the cages and the natural environment in the present study. While juvenile crabs are abundant in kelp habitats, coralline algal habitats (similar to this site) in the adjacent Gulf of Maine also had low densities of juvenile crabs (McNaught 1999).The most common carnivorous species in the cages were scale worms; however, laboratory studies found that the scale worm Lepidonotus squamatus did not consume sea urchins Strongylocentrotus droebachiensis $(<1.3 \mathrm{~mm})$ (Scheibling \& Robinson 2008).

Consumption by omnivorous grazers is possibly responsible for the greater mortality in the cages with the suite of animals. The suite contained many mobile omnivorous species that may have consumed the small (1 to $3 \mathrm{~mm}$ ) sea urchins. Larger sea urchins and chitons were both abundant members of the suite and are both omnivorous grazers with the potential to consume small sea urchins (Langer 1983, Briscoe \& Sebens 1988).

Recently settled sea urchins may also be subject to bulldozing (crushing by grazers). Bulldozing is known to be a source of early post-settlement mortality for a number of species (reviewed by Hunt \& Scheibling 1997). In the laboratory, $36 \%$ of early post-settlement sea urchins were damaged and killed due to bulldozing by the snail Littorina littorea (Scheibling \& Robinson 2008). In the present study, larger juvenile sea urchins and chitons were part of the suite and may have bulldozed the small sea urchins, resulting in broken tests, abrasion of spines and death. Sea urchins are known to bulldoze other species such as corals and sponges (e.g. Sammarco 1980, Maldonado \& Uriz 1998).

The demi-pyramids of juvenile sea urchins grew larger in no-suite cages. Animals in the suite may have affected the growth of small sea urchins either directly by competing for resources or indirectly by limiting foraging behaviour. Both larger juvenile sea urchins and chitons, which likely consume the same foods as recently settled sea urchins, are possible competitors. Chemical cues of predators or damaged conspecifics can cause sea urchins to flee or reduce foraging behaviours (e.g. Mann et al. 1984, Vadas \& Elner 2003, Matassa 2010). Juvenile Strongylocentrotus droebachiensis tend not to move (Nishizaki \& Ackerman 2006) and have less growth in the presence of predator cues (Selden et al. 2009).

The addition of kelp had different results in the withsuite and no-suite treatments; it is possible that competition for food was more intense in the with-suite treatments, while food in the no-suite treatment was abundant (e.g. biofilms), regardless of the addition of kelp. Nishizaki \& Ackerman (2004) found that the juvenile sea urchins Strongylocentrotus droebachiensis and $S$. franciscanus grew less when both kelp and 
conspecific adults were present, suggesting intercohort competition, although generally sea urchins grow better when fed kelp than coralline algae or bare rocks (e.g. Briscoe \& Sebens 1988, Rowley 1990, Jennings 2011).

Sea stars Asteria spp. showed a different pattern of mortality in the caging experiment than did sea urchins; they survived better in cages where other species were present. This is different from the sea stars Acanthaster planci and Nardoa novaecaladoniae, which had greater survival in cages where the other animals had been removed from coral rubble, likely due to the abundance of predators in the community (Keesing \& Halford 1992, Keesing et al. 1996). While interspecific competition can cause small adult Asterias rubens to reduce their feeding rates in the laboratory (Gaymer et al. 2002), the present study gives no evidence for interspecific competition. In our study, sea stars had a different cause of mortality, possibly starvation, intraspecific (intrageneric) competition for food and/or cannibalism. Although out in the field longer, with-suite cages in the sea urchin experiment had twice the densities of bivalves and chitons compared to the sea star with-suite cages, suggesting consumption of the other animals by sea stars. In the no-suite cages, the only food sources available were the biofilm, the other sea stars, or the few small animals (such as encrusting bryozoans) that had settled into the cages. While adult sea stars can consume biofilms and bryozoans (Keough \& Butler 1979, Scheibling \& Lauzon-Guay 2006), the nutritional value of these foods for recent settlers is unknown. The main food source for the juvenile sea stars in the no-suite cages was likely conspecifics. Both $A$. rubens and $A$. forbesi will resort to cannibalism when other food resources are exhausted (Menge 1979, Witman et al. 2003). The juvenile sea stars in this experiment were likely starving in the no-suite treatments and therefore had to compete for the limited food resources or resort to cannibalism.

Overall, a higher percent of the sea stars $(82.4 \pm$ $4.1 \%)$ died in the cages than did sea urchins (33.8 \pm $4.1 \%$ ). Sea stars have previously been observed at this site to have a greater natural decline than sea urchins over the first few months after settlement (Jennings \& Hunt 2009). Similar trends were seen in a natural assemblage of echinoderms in a field study $\sim 250 \mathrm{~km}$ away in Nova Scotia, Canada, where sea stars had greater declines in abundance between settlement and recruitment than sea urchins in rocky barrens (Balch \& Scheibling 2000). The difference in the mortality of sea stars and sea urchins in this caging experiment is likely ecological, since the sea stars are predators and sea urchins are omnivores (e.g. Briscoe \& Sebens 1988, Wong \& Barbeau 2003).
The percent decline of abundance of sea stars was similar between the natural environment and the cages; however, the abundance of recently settled sea urchins declined more in the cages than in the natural environment. These results need to be interpreted with caution since the quadrats encompass spatial and temporal variation, while the cages only include temporal variation. However, the presence of the cage may alter biological and physical factors that can affect early post-settlement mortality in the cage (e.g. Baria et al. 2010). The animals in the cages may have eaten more juvenile sea urchins than they would naturally because other prey sources were limited, since immigration was not possible in the closed cages. It is also possible that the cages may have excluded larger predators that would have consumed or changed the behaviour of the juvenile sea urchin predators (Siddon \& Witman 2004, Guidetti 2007). Physical differences such as the flow of water or sunlight penetration could have also caused differences in declines between the cages and the natural environment. Flow in the cages (without the lid) was only $10 \%$ of that outside the cage for slower flow speeds $\left(5 \mathrm{~cm} \mathrm{~s}^{-1}\right)$ when tested in a flume (measured with a Sontek micro ADV current meter $5 \mathrm{~cm}$ from the cobble bottom; authors' unpubl. data). Near the study site, measured flow speeds averaged $6.8 \mathrm{~cm} \mathrm{~s}^{-1}$ (Blythe Chang, Dept. of Fisheries and Oceans, Canada, pers. comm.), resulting in expected mean flow speeds of $0.7 \mathrm{~cm} \mathrm{~s}^{-1}$ in the cages. While low flow can result in low oxygen levels, this was not likely a problem as no mass mortality or anoxia was seen in the cages and the sea urchins appeared healthy. However, it is possible that the low flow in the cages may have affected some of the other animals, and indirectly affected the mortality of the sea urchins. The amount of sunlight is another physical parameter that differed between the covered cages and the natural environment. Sea urchins will cover themselves when exposed to UV light (Dumont et al. 2007), a behaviour which may reduce their mobility and, therefore, their susceptibility to predation or bulldozing. Biofilms (a potential food source) subject to more sunlight tend to have faster growth rates and a greater diversity of organisms (Rao et al. 1997). Therefore, the greater mortality in the cages compared to the natural environment could be caused by sampling, or biological or physical differences.

It is obvious that interactions with other small benthic macroinvertebrates are important for the survival of recently settled sea urchins and sea stars and the growth of sea urchins. These results suggest that predation by carnivores is not the most likely cause of early post-settlement mortality, but that predation by omnivorous grazers or bulldozing may be important for young sea urchins and intraspecific/intrageneric competition, starvation and/or cannibalism is important for 
small sea stars. Additional studies are needed to further understand the interactions between recently settled echinoderms and their communities. Interactions with individual species within the community should be examined to determine who the competitors, bulldozers and predators of young juvenile sea urchins are. Also, other resources, such as biofilm and coralline algae, should be manipulated to determine if interspecific competition for different resources exists. Experiments with various densities of sea stars and the addition of food should be done to learn more about intraspecific/intrageneric competition and cannibalism in this group. Overall, the results of the present study suggest that interactions with members of the community are important for the success of recently settled echinoderms in shallow cobble habitats and that species, even from the same phylum and habitat, do not experience early post-settlement processes equally.

Acknowledgements. We thank everyone who helped us in the field and the laboratory: M.-J. Maltais, M. Shaver, B. Morse, J. Ellsworth, M. Sprague, M. Boulanger, A.-C. Vallejo, C. Weinheimer, J. Cuillerier, E. Holtz, C. Titley-O'Neal, C. Arens and M. Pokorski. We also thank J. Houlahan and M. Barbeau and 3 anonymous reviewers for their comments on this manuscript. Funding for this project was provided by an NSERC-PGS D award to L.B.J. and an NSERC Discovery Grant to H.L.H.

\section{LITERATURE CITED}

Andrew NL, Choat JH (1982) The influence of predation and conspecific adults on the abundance of juvenile Evechinus chloroticus (Echinoidea: Echinometridae). Oecologia 54: 80-87

Aukema BH, Raffa KF (2002) Relative effects of exophytic predation, endophytic predation, and intraspecific competition on a subcortical herbivore: consequences to the reproduction of Ips pini and Thanasimus dubius. Oecologia 133:483-491

Balch T, Scheibling RE (2000) Temporal and spatial variability in settlement and recruitment of echinoderms in kelp beds and barrens in Nova Scotia. Mar Ecol Prog Ser 205: 139-154

Baria MVB, Guest JR, Edwards AJ, Alino PM, Heyward AJ, Gomez ED (2010) Caging enhances post-settlement survival of juveniles of the scleractinian coral Acropora tenuis. J Exp Mar Biol Ecol 394:149-153

Beal BF (2006) Relative importance of predation and intraspecific competition in regulating growth and survival of juveniles of the soft-shell clam, Mya arenaria L., at several spatial scales. J Exp Mar Biol Ecol 336:1-17

Birch LC (1957) The meanings of competition. Am Nat 91: $5-18$

Briscoe CS, Sebens KP (1988) Omnivory in Strongylocentrotus droebachiensis (Muller) (Echinodermata: Echinoidea): predation on subtidal mussels. J Exp Mar Biol Ecol 115: $1-24$

Clarke KR, Warwick RM (2001) Change in marine communities: an approach to statistical analysis and interpretation, 2nd edn. PRIMER-E, Plymouth
Creese RG (1982) Distribution and abundance of the acmaeid limpet, Patelloida latistrigata, and its interaction with barnacles. Oecologia 52:85-96

> Dayton PK (1971) Competition, disturbance, and community organization: the provision and subsequent utilization of space in a rocky intertidal community. Ecol Monogr 41: 351-389

Dumont CP, Drolet D, Deschenes I, Himmelman JH (2007) Multiple factors explain the covering behaviour in the green sea urchin, Strongylocentrotus droebachiensis. Anim Behav 73:979-986

Ebert TA (2001) Growth and survival of post-settlement sea urchins. In: Lawrence JM (ed) Edible sea urchins: biology and ecology. Elsevier Science B.V., Amsterdam, p 79-102

Gaymer CF, Himmelman JH, Johnson LE (2002) Effect of intra- and interspecific interactions on the feeding behavior of two subtidal sea stars. Mar Ecol Prog Ser 232: $149-162$

Gosselin LA, Qian PY (1997) Juvenile mortality in benthic marine invertebrates. Mar Ecol Prog Ser 146:265-282

Griffiths AM, Gosselin LA (2008) Ontogenetic shift in susceptibility to predators in juvenile northern abalone, Haliotis kamtschatkana. J Exp Mar Biol Ecol 360:85-93

Guidetti P (2007) Predator diversity and density affect levels of predation upon strongly interactive species in temperate rocky reefs. Oecologia 154:513-520

Harris LG, Rice B, Nestler EC (1994) Settlement, early survival and growth in a southern Gulf of Maine population of Strongylocentrotus droebachiensis (Muller). In: David B, Guille A, Feral J-P, Roux M (eds) Echinoderms through time. Balkema, Rotterdam, p 701-706

> Hunt HL, Scheibling RE (1997) Role of early post-settlement mortality in recruitment of benthic marine invertebrates. Mar Ecol Prog Ser 155:269-301

Jennings LB (2011) Early post-settlement mortality, growth and behaviour of sea urchins Strongylocentrotus droebachiensis and sea stars Asterias spp. in shallow subtidal cobble habitats. $\mathrm{PhD}$ dissertation, University of New Brunswick, Saint John

Jennings LB, Hunt HL (2009) Settlement, recruitment and potential predators and competitors of juvenile echinoderms in the rocky subtidal zone. Mar Biol 157:307-316

Kautsky N (1982) Growth and size structure in a Baltic Mytilus edulis population. Mar Biol 68:117-133

> Keesing JK, Halford AR (1992) Field measurement of survival rates of juvenile Acanthaster planci: techniques and preliminary results. Mar Ecol Prog Ser 85:107-114

Keesing JK, Wiedemeyer WL, Okaji K, Halford AR, Hall KC, Cartwright CM (1996) Mortality rates of juvenile starfish Acanthaster planci and Nardoa spp. measured on the Great Barrier Reef, Australia and in Okinawa, Japan. Oceanol Acta 19:441-448

Keough MJ, Butler AJ (1979) The role of asteroid predators in the organization of a sessile community on pier pilings. Mar Biol 51:167-177

Lamare MD, Mladenov PV (2000) Modelling somatic growth in the sea urchin Evechinus chloroticus (Echinoidea: Echinometridae). J Exp Mar Biol Ecol 243:17-43

Langer PD (1983) Diet analysis for three subtidal coexisting chitons from the northweastern Atlantic (Mollusca: Polyplacophora). Veliger 25:370-377

Maldonado M, Uriz MJ (1998) Microrefuge exploitation by subtidal encrusting sponges: patterns of settlement and post-settlement survival. Mar Ecol Prog Ser 174:141-150

Mann KH, Wright JLC, Welsford BE, Hatfield E (1984) Responses of the sea urchin Strongylocentrotus droebachiensis (O.F. Muller) to water-borne stimuli from 
potential predators and potential food algae. J Exp Mar Biol Ecol 79:233-244

Marsden ID (2002) Recruitment in the swash zone - temporal variations in juvenile recruitment of an exposed sand beach surf clam. Hydrobiologia 477:47-57

Matassa CM (2010) Purple sea urchins Strongylocentrotus purpuratus reduce grazing rates in response to risk cues from the spiny lobster Panulirus interruptus. Mar Ecol Prog Ser 400:283-288

McNaught DC (1999) The indirect effects of macroalgae and micropredation on the post-settlement success of the green sea urchin in Maine. $\mathrm{PhD}$ dissertation, University of Maine, Orono, ME

Menge BA (1979) Coexistence between the seastars Asterias vulgaris and $A$. forbesi in a heterogeneous environment: a non-equilibrium explanation. Oecologia 41:245-272

Nishizaki MT, Ackerman JD (2004) Juvenile-adult associations in sea urchins Strongylocentrotus franciscanus and S. droebachiensis: Is nutrition involved? Mar Ecol Prog Ser 268:93-103

Nishizaki MT, Ackerman JD (2006) Juvenile-adult associations in sea urchins (Strongylocentrotus franciscanus and $S$. droebachiensis): protection from predation and hydrodynamics in S. franciscanus. Mar Biol 151:135-145

Rao TS, Rani PG, Venugopalan VP, Nair KVK (1997) Biofilm formation in a freshwater environment under photic and aphotic conditions. Biofouling 11:265-282

Rowley RJ (1990) Newly settled sea urchins in a kelp bed and urchin barren ground: a comparison of growth and mortality. Mar Ecol Prog Ser 62:229-240

Russell MP (2001) Spatial and temporal variation in growth of the green sea urchin, Strongylocentrotus droebachiensis, in the Gulf of Maine, USA. In: Barker M (ed) Echinoderms 2000 - Proceedings of the 10th international echinoderm conference. A.A. Balkema, Rotterdam, p 533-538

Russell MP, Urbaniak LM (2004) Does calcein affect estimates of growth rates in sea urchins? In: Heinzeller, Nebelsick (eds) Echinoderms: Munchen. Taylor \& Francis Group, London, p 53-57

Sammarco PW (1980) Diadema and its relationship to coral

Editorial responsibility: Richard Osman,

Edgewater, Maryland, USA spat mortality: grazing, competition, and biological disturbance. J Exp Mar Biol Ecol 45:245-272

Scheibling RE (1996) The role of predation in regulating sea urchin populations in eastern Canada. Oceanol Acta 19: 421-430

Scheibling RE, Lauzon-Guay JS (2006) Feeding aggregations of sea stars (Asterias spp. and Henricia sanguinolenta) associated with sea urchin (Strongylocentrotus droebachiensis) grazing fronts in Nova Scotia. Mar Biol 151: 1175-1183

Scheibling RE, Robinson MC (2008) Settlement behaviour and early post-settlement predation of the sea urchin Strongylocentrotus droebachiensis. J Exp Mar Biol Ecol 365:59-66

Selden R, Johnson AS, Ellers O (2009) Waterborne cues from crabs induce thicker skeletons, smaller gonads and sizespecific changes in growth rate in sea urchins. Mar Biol 156:1057-1071

Siddon CE, Witman JD (2004) Behavioral indirect interactions: multiple predator effects and prey switching in the rocky subtidal. Ecology 85:2938-2945

Silina AV (2008) Long-term changes in intra- and inter-specific relationships in a community of scallops and sea stars under bottom scallop mariculture. J Shellfish Res 27: 1189-1194

Tomas F, Romero J, Turon X (2005) Experimental evidence that intra-specific competition in seagrass meadows reduces reproductive potential in the sea urchin Paracentrotus lividus (Lamarck). Sci Mar 69:475-484

Vadas RL, Elner RW (2003) Responses to predation cues and food in two species of sympatric, tropical sea urchins. PSZNI: Mar Ecol 24:101-121

> Witman JD, Genovese SJ, Bruno JF, McLaughlin JW, Pavlin BI (2003) Massive prey recruitment and the control of rocky subtidal communities on large spatial scales. Ecol Monogr 73:441-462

- Wong MC, Barbeau MA (2003) Effects of substrate on interactions between juvenile sea scallops (Placopecten magellanicus Gmelin) and predatory sea stars (Asterias vulgaris Verrill) and rock crabs (Cancer irroratus Say). J Exp Mar Biol Ecol 287:155-178

Submitted: August 27, 2010; Accepted: March 15, 2011 Proofs received from author(s): May 18, 2011 